\title{
International Students' Perceived Language Competence, Domestic Student Support, and Psychological Well-Being at a U.S. University
}

\author{
Zhengda Luo \\ Siyu Wu \\ Xuanyu Fang \\ Nelson C. Brunsting \\ Wake Forest University
}

\begin{abstract}
To increase knowledge of international students' psychological well-being at U.S. universities, we examined the degree to which demographic factors, perceived language competence, and domestic student social support were associated with Ryff's (1989a, 1989b) six aspects of psychological well-being. Participants $(n=216)$ were undergraduate and graduate students from one mid-sized private university in the Southeast. Analyses revealed differential psychological well-being scores based on demographics. Perceived language competence and domestic student social support were associated positively with multiple aspects of psychological well-being. The novel findings of this case study provide initial evidence of a potentially useful new approach toward international student adjustment and well-being. The authors provide initial recommendations for researchers, practitioners, and international students.
\end{abstract}

Keywords: college or university, international student, language competence, psychological well-being, social support, United States

The steady increase of international students - students without United States (US) passports studying on visas - at colleges and universities in the US over the last two decades has coincided with greater research attention on international student adjustment (International Institute for Education, 2017; Smith \& Khawaja, 2011). 
This focus on international students' university experience has illuminated the successes and challenges students from across the globe encounter in the US, with the greatest attention afforded to psychosocial outcomes such as acculturative stress, anxiety, and depression (Brunsting, Zachry, \& Takeuchi, 2018; J. Zhang \& Goodson, 2011). Potentially lost in the exploration of negative adjustment outcomes is the opportunity to better comprehend more positive psychosocial outcomes such as wellbeing. The current study is designed to explore demographic, social, and academic factors associated with psychological well-being, specifically six subtypes of wellbeing: autonomy, purpose in life, positive relations with others, environmental mastery, self-acceptance, and growth. To increase the knowledge base of positive well-being outcomes for international students, we selected - based on theory and prior research - variables of interest: perceived language competence and domestic student social support. Domestic student social support represents the degree to which international students perceive the U.S. students on their campus are willing to help them when needed and include them in opportunities. To date, no research has investigated linkages between perceived language competence, domestic student social support, and specific aspects of psychological well-being.

Following Ryff (1989a, 1989b), psychological well-being is drawn from an integrated framework of life course theory, mental health perspectives, and personal growth theories and has extended prior approaches focused mainly on happiness or affect. Ryff posited six aspects of psychological well-being: autonomy, environmental mastery, personal growth, positive relations with others, selfacceptance, and purpose in life. Autonomy is the degree to which one is the locus of control and is self-directed in one's actions. Environmental mastery represents the degree to which one can arrange one's environment satisfactorily. Personal growth relates to one's feeling of continuous growth and development on one's path to selfactualization. Those who are self-accepting acknowledge both their good and bad qualities, generally having a positive self-regard. Purpose in life refers to feeling one has a direction, usually positive, in life and that life generally has meaning.

Recent literature reviews on international student adjustment, acculturative stress, and well-being concur in their summaries of the international student experience: Many international students adjust well to the new academic, cultural, and social environment at the university and have positive well-being outcomes; however, a substantial portion of international students encounter a range of challenges and experience lower well-being (Alharbi \& Smith, 2018; Brunsting, Zachry, \& Takeuchi, 2018; J. Li, Wang, \& Xiao, 2014; Smith \& Khawaja, 2011; J. Zhang \& Goodson, 2011). Frequent challenges include social support, English language competence or proficiency, attitudes toward help-seeking and self-efficacy; additional factors associated with well-being include country of origin, personality, and length of time in host country (Alharbi \& Smith, 2018; Brunsting et al., 2018; J. Li et al., 2014; J. Zhang \& Goodson, 2011). The current study draws on cross-cultural adjustment to identify two primary factors in international student adjustment: perceived language competence and domestic student social support. 


\section{THEORETICAL FRAMEWORK}

Ward and colleagues' (Ward \& Kennedy, 1999; Ward \& Rana-Deuba, 1999) theory of cross-cultural adjustment partitions adjustment into two domains: psychological (i.e., psychological well-being and satisfaction with one's ability to navigate a new environment) and sociocultural (i.e., one's ability to "fit in" and be welcomed by the host culture). The theory posits that factors such as social support and personality promote psychological adjustment while language fluency and social skills are associated with sociocultural adjustment. However, researchers have noted that some international student factors (e.g., length of residence in the US, acculturation) are associated with both psychological and sociocultural outcomes, which brings into question the degree to which psychological and sociocultural aspects of adjustment interact or are jointly predicted (J. Zhang \& Goodson, 2011). The current study is designed to test an aspect of the theory of cross-cultural adjustment: Are both psychological and sociocultural factors-domestic student social support and perceived language competence - associated with international students' psychological well-being when controlling for demographic factors? Figure 1 illustrates the framework as posited by Ward and colleagues (Ward \& Kennedy, 1999; Ward \& Rana-Deuba, 1999).

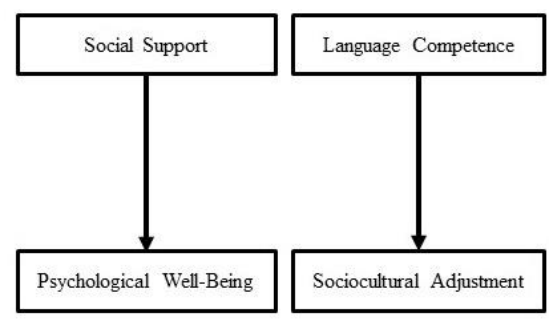

(a)

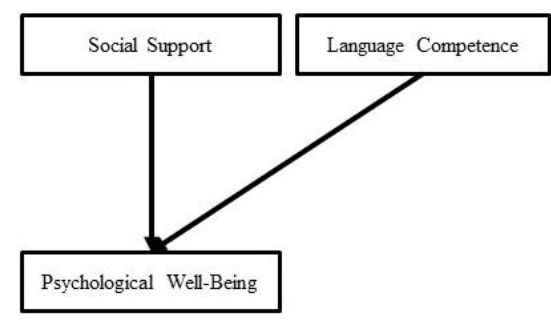

(b)

Figure 1: The first model (a) represents a simplified framework of Ward and Kennedy's (1999) Theory of Cross-Cultural Adaptation, which includes the variables of interest in the current study. The second model (b) is tested in the current study.

\section{Perceived Language Competence and Well-Being}

Host country language competence is an essential factor associated with international students' well-being in their adjustment process. In order to pursue successful interaction with members of the host culture, international students may need to adjust their attitudes and social behavior at times to fit in to the local environment and society. Investigations of international students' acculturation process revealed that self-reported English language proficiency is a significant predictor of acculturative stress, depression, and psychological distress (Mahmood \& Burke, 2018; Smith \& Khawaja, 2014). Low academic-achieving international students reported a low English proficiency and greater overall stress (de Araujo, 
2011; Sümer, Poyrazli, \& Grahame, 2008; C.-C. D. Wang \& Mallinckrodt, 2006; K. T. Wang et al., 2012). They encountered more challenges in understanding class context, participating in discussions, and communicating concerns. In particular, low language proficiency may affect international students' procrastination behavior, leading to increasing stress and decreasing quality of academic performance (J. Zhang \& Goodson, 2011). A recent study documented students' perceptions of their growth as their language skills progressed during studying in the US: Chinese international students reported greater self-confidence, maturity, and independence as well as increased English ability ( $\mathrm{Z}$. Li et al., 2017). These outcomes align with the psychological wellbeing subscales of self-acceptance, environmental mastery, and positive relations, providing support for the hypothesis that perceived language competence will by associated with self-acceptance, environmental mastery, and positive relations.

\section{Perceived Language Competence and Domestic Students' Social Support}

International students may experience anxiety and isolation because of language barriers (Ching, Renes, McMurrow, Simpson, \& Strange, 2017). Although language proficiency is believed to be a significant factor of social well-being, research suggests that individuals' perception of their language competency rather than actual language competence is related to acculturative outcomes (Lin \& Betz, 2009). For Taiwanese students in the US, English proficiency mediated the effects of acculturation level (Dao, Lee, \& Chang, 2007); similarly, Turkish students' selfreported English difficulties predicted their adjustment (Yildirim, 2015). However, other previous findings show that the level of English proficiency did not mediate the effect of social support on the level of acculturative stress (Poyrazli, Kavanaugh, Baker, \& Al-Timimi, 2004). Socially a lack of confidence in one's second language ability may undermine international students' social self-efficacy and social ability. Indeed, social self-efficacy in the English setting is significantly and positively related to English proficiency (Constantine, Okazaki, \& Utsey, 2004; Lin \& Betz, 2009). Typically, these challenges beget further challenges, as difficulty communicating with members of the host culture impedes communication of necessary information and can lead to decreases in satisfaction with life in United States for international students (J. Zhang \& Goodson, 2011). A recent study of international students in Australia revealed associations between English language proficiency, support from host country (e.g., university faculty, staff, and students; locals), and student satisfaction with university life (Mak, Bodycott, \& Ramburuth, 2015). The current study is designed to replicate and extend research in this area by testing whether perceived language competence is associated with domestic student social support rather than a broader construct of host country support.

\section{Domestic Student Social Support and Well-Being}

Domestic student social support may be an important predictor of international students' psychological wellbeing. Previous research suggests that students who selfreport a high level of social support have a lower level of acculturative stress (Yeh \& 
Inose, 2003). When international students leave their home country, they are often disconnected with their previous social support system. However, the challenge of building a new social network can be difficult for international students compared to the local groups (Longerbeam, DeStefano, \& Lixin, 2013; Poyrazli \& Grahame, 2007) and many report feeling social isolation (MacLachlan \& Justice, 2009). We anticipate that social support from domestic students may help them to establish new relationships. Given the benefits of support from local students for succeeding in a new environment, we expect domestic student social support will be associated with psychological well-being constructs of positive relationships with others, environmental mastery, and autonomy. A recent study examined the degree to which university support (i.e., support from university, faculty, and staff) related to student academic, social, physical, and psychological well-being, finding that university support predicted higher scores on well-being generally (Chavoshi, Wintre, Dentakos, \& Wright, 2017). However, Chavoshi et al. (2017) did not explore associations between university support and the psychological well-being subscale. The current study extends the current research by testing for relationships domestic student social support and six aspects of psychological well-being.

\section{Hypotheses}

1. Domestic student social support will have a significant positive association with perceived language competence for international students.

2. Higher levels of perceived language competence will be associated with increases on three of six subscales of psychological well-being of international students aligned with communication and confidence of speaking (self-acceptance, environmental mastery, and positive relationship), as well as the overall psychological wellbeing.

3. Domestic student social support will be associated positively with three of six aspects of psychological well-being of international students: autonomy, environmental mastery, and positive relationships with others, as well as the overall psychological wellbeing.

4. Domestic student social support will have a stronger positive association than perceived language competence for each psychological well-being outcome.

\section{METHODS}

\section{Participants}

In the current study, the participants were 216 international students at a small liberal arts university in the Southeast. Table 1 includes the demographic information for participants. The age range of participants varied from 17 to 38 with an average 
of 21.37. Most of the international students in this study came from East Asian countries with citizenships $(n=171 ; 79.16 \%)$. Chinese students consisted of a large portion of student body from East Asian, $(n=160 ; 93.57 \%)$, and of all participants in the study (74.54\%). Most participants were undergraduate students $(n=124 ; 57.4 \%)$ and female $(n=156 ; 72.2 \%)$.

Table 1: Participant Demographic Information

\begin{tabular}{|c|c|c|c|c|c|}
\hline Participants & $n$ & $\%$ & & $n$ & $\%$ \\
\hline \multicolumn{3}{|l|}{ Gender } & \multicolumn{3}{|l|}{ Degree Pursued } \\
\hline Male & 60 & 27.8 & Bachelors & 124 & 57.4 \\
\hline Female & 156 & 72.2 & Masters (non-MBA) & 68 & 31.5 \\
\hline \multicolumn{3}{|l|}{ Citizenship } & MBA & 4 & 1.9 \\
\hline N. and Centr. America & 7 & 3.2 & $\mathrm{JD}$ & 1 & 0.5 \\
\hline South America & 12 & 5.6 & $\mathrm{PhD}$ & 19 & 8.8 \\
\hline Europe & 12 & 5.6 & \multicolumn{3}{|c|}{ Year: Undergraduates } \\
\hline Africa & 4 & 1.9 & 1 & 34 & 27.4 \\
\hline Middle East & 2 & 0.9 & 2 & 27 & 21.8 \\
\hline Central Asia (India) & 9 & 0.4 & 3 & 37 & 29.8 \\
\hline East Asia & 170 & 78.7 & 4 & 26 & 21.0 \\
\hline \multicolumn{3}{|l|}{ Citizen of China } & \multicolumn{3}{|l|}{ Year: Graduates } \\
\hline Yes & 160 & 74.1 & 1 & 54 & 60.7 \\
\hline \multirow[t]{5}{*}{ No } & 56 & 25.9 & 2 & 19 & 21.3 \\
\hline & & & 3 & 6 & 6.7 \\
\hline & & & 4 & 6 & 6.7 \\
\hline & & & 5 & 2 & 2.2 \\
\hline & & & $6+$ & 2 & 2.2 \\
\hline
\end{tabular}

\section{Procedure}

Prior to recruiting participants, we obtained approval from our institutional review board. Names and emails of all international students at the participating university were obtained from the university registrar. The fourth author sent out a series of three recruitment emails asking students to participate in the study and complete the linked survey. The survey took $15-25 \mathrm{~min}$ for the participants to complete; those who completed were entered into drawings for one of five $\$ 50$ gift cards. All participants were aged 16 or above and all surveys were finished within 5 weeks between October 1 and November 5 in 2017. The response rate of participants was $30.64 \%$.

\section{Measures}

\section{Demographics}

The survey contained a series of demographic questions, including age, gender, home country, citizenship, degree pursued (e.g., graduate or undergraduate) and 
location of country in which the participant graduated high school. As participants only selected two of the five options for gender, we coded gender as a binary variable (e.g., female or male) in this survey.

\section{Domestic Student Social Support}

To measure domestic student social support, or the perception of support internationals students felt they received from American students at their university, we adapted the Social Support Scale (Carver, 2006) in two ways. First, we removed four items that were deemed to be confusing by a focus group of international students. Second, we adapted the stem of the social support questions to focus on domestic students. An example question is "how much you can relax and be yourself around the American students at your university?". The scale ranged from 1 (none) to 5 (a great deal) and demonstrated high reliability $(\alpha=.93)$.

\section{Psychological Well-Being}

The survey included the 42-item Ryff's (1989a, 1989b) Psychological WellBeing Scale, comprised of six subscales: purpose in life, positive relations with others, autonomy, environmental mastery, personal growth, and self-acceptance. Example items include "I do not have many people who want to listen when I need to talk" and "It is difficult for me to voice my opinions of controversial matters." Participants responded on a five-point Likert-type scale ranging from 1 (strongly disagree) to 5 (strongly agree). The subscales demonstrated moderate to high reliability in the current sample, ranging from .70 (autonomy) to .79 (personal growth); the full 42-item scale had high reliability $(\alpha=.91)$.

\section{Perceived Language Competence}

Perceived language competence is derived from a single item. Students were asked to predict the degree to which they felt they were incompetent in English. The response option was a slider ranging from 0 not at all characteristic to 10 extremely characteristic, with options to one decimal place (e.g., 6.8). This response was then reverse coded to produce the perceived language competence variable.

\section{Plan of Analysis}

To prepare the data for regression analyses, we first examined the dataset for diversions from univariate and multivariate normality, issues of multicollinearity, and reliability of measures. No items exceeded recommended thresholds for skewness or kurtosis ( \pm 2 and \pm 5 , respectively; Ware, Ferron, \& Miller, 2013). After examining Mahalanobis' distances, no multivariate outliers were identified. Variance inflation factors were calculated to assess for issues of multicollinearity for the planned regression. As no variance inflation factor exceeded 1.2-well below the recommended threshold of 3-this suggests the variables are not multicollinear. Measure reliability was assessed with Cronbach's alphas: Multiple-item measures ranged from .71 to .93 , demonstrating good reliability. We conducted two series of 
ordinary least squares regression analyses to determine first whether perceived language competence would predict changes in the six constructs of psychological well-being as well as the overall construct, controlling for demographic differences. The second series of regression analyses included all the variables in the first series as well as an additional independent variable: domestic student social support.

\section{RESULTS}

We conducted Pearson correlations and two sets of ordinary least squares regression analyses to examine first whether self-perceived language competence would be associated positively with aspects of psychological well-being, controlling for demographic differences among participants (see Table 2). After the first set of regression analyses revealed significant relationships between perceived language competence, domestic student social support was added to the regression model as an additional independent variable.

Table 2: Summary of Intercorrelations of Six Subscales of Psychology WellBeing, Socioeconomic Status (SES), Domestic Social Support, and Language Competence of International Students in U.S. Universities

\begin{tabular}{|c|c|c|c|c|c|c|c|c|c|c|c|}
\hline Measure & 1 & 2 & 3 & 4 & 5 & 6 & 7 & 8 & 9 & $M$ & $S D$ \\
\hline SES & - & & & & & & & & & 5.95 & 1.62 \\
\hline $\begin{array}{l}\text { Language } \\
\text { competence }\end{array}$ & $-.30 * * *$ & - & & & & & & & & 3.91 & .83 \\
\hline $\begin{array}{l}\text { Domestic social } \\
\text { support }\end{array}$ & $.18 *$ & -.11 & - & & & & & & & 2.23 & .85 \\
\hline Autonomy & $.22 *$ & $-.31 * * *$ & $.16^{*}$ & - & & & & & & 6.28 & 4.94 \\
\hline $\begin{array}{l}\text { Positive } \\
\text { relations with } \\
\text { others }\end{array}$ & .14 & $-.23 * *$ & $.25 * *$ & .10 & - & & & & & 2.58 & 3.17 \\
\hline $\begin{array}{l}\text { Environmental } \\
\text { mastery }\end{array}$ & .14 & $-.19=$ & $.28 * * *$ & $.24 * *$ & $.51^{* * *}$ & - & & & & 3.58 & 3.38 \\
\hline Personal growth & .09 & $-.17 *$ & $.18 *$ & $.16^{*}$ & $.43^{* * * *}$ & $.42^{* * * *}$ & - & & & 3.49 & .82 \\
\hline Purpose of life & .08 & $-.22 * *$ & $.22 * s$ & $.35 * * *$ & $.39 * * *$ & $.58^{* * * *}$ & $.62^{* * * *}$ & - & & 3.06 & .90 \\
\hline Self-acceptance & $.28^{* * *}$ & $-.31^{* s *}$ & $.26 *+*$ & $.35^{* * * *}$ & $.55^{* * * *}$ & $.60^{* * * *}$ & $.47 * * *$ & $.53^{* * *}$ & - & 3.49 & .92 \\
\hline $\begin{array}{l}\text { Psychological } \\
\text { well-being }\end{array}$ & $.22^{* *}$ & $-.32 * * *$ & $.32 * * *$ & $.50 * * *$ & $.69^{* * *}$ & $.77 * * *$ & $.72 * * *$ & $.80^{* * * *}$ & $.82^{* * *}$ & 21.67 & 3.04 \\
\hline
\end{tabular}

Note. $* p<.05, * * p<.01, * * * p<.001$.

As expected, there were significant negative correlations between perceived language competence and well-being outcomes as well as between significant positive correlations between domestic student social support and well-being outcomes. Interestingly, the relationship between perceived language competence and domestic student social support was nonsignificant.

\section{Perceived Language Competence and Well-Being}

Seven regression analyses were calculated to test for predictive associations between perceived language competence and six subscales of psychological wellbeing as well as an aggregated psychological well-being variable, all controlling for demographic differences. See Table 3 for the results. Perceived language competence 
and the four demographic variables accounted for between $5 \%$ and $17 \%$ of the variance in psychological well-being subscales: psychological well-being (17\%), self-acceptance $(16 \%)$, autonomy $(15 \%)$, purpose in life $(13 \%)$, personal growth (10\%), positive relations with others (10\%), and environmental mastery (5\%). In five of the equations, significant relationships were revealed between perceived language competence and psychological well-being, with higher levels of perceived English incompetence associated with increases in well-being.

Table 3: Psychological Well-Being Subscales Predicted by Domestic Social Support and Perceived Language Competence

\begin{tabular}{|c|c|c|c|c|c|}
\hline Outcome & Predictors & $\beta$ & $S E$ & $t$ & $p$ \\
\hline \multicolumn{6}{|c|}{ Autonomy } \\
\hline \multirow{6}{*}{$R_{2}=.16$} & Chinese & -.08 & .12 & -1.06 & .29 \\
\hline & Female & -.12 & .11 & -1.67 & .10 \\
\hline & Undergraduate & -.08 & .10 & -1.06 & .29 \\
\hline & SES & .15 & .03 & 1.95 & .05 \\
\hline & Language competence & .21 & .02 & 2.66 & $.01 * *$ \\
\hline & Domestic social support & .14 & .06 & 1.91 & .06 \\
\hline \multicolumn{6}{|c|}{ Positive relations with others } \\
\hline \multirow{6}{*}{$R_{2}=.12$} & Chinese & .06 & .13 & .72 & .47 \\
\hline & Female & .14 & .11 & 1.88 & .06 \\
\hline & Undergraduate & -.08 & .11 & -1.05 & .30 \\
\hline & SES & .06 & .04 & .80 & .43 \\
\hline & Language competence & .22 & .02 & 2.69 & $.01 * *$ \\
\hline & Domestic social support & .21 & .06 & 2.86 & $.01 * *$ \\
\hline \multicolumn{6}{|c|}{ Environmental mastery } \\
\hline \multirow{6}{*}{$R_{2}=.11$} & Chinese & .07 & .13 & .88 & .38 \\
\hline & Female & .07 & .12 & .87 & .39 \\
\hline & Undergraduate & -.10 & .11 & -1.27 & .21 \\
\hline & SES & .09 & .04 & 1.12 & .26 \\
\hline & Language competence & .17 & .02 & 1.99 & $.05 *$ \\
\hline & Domestic social support & .24 & .06 & 3.14 & $.00 * *$ \\
\hline \multicolumn{6}{|c|}{ Personal growth } \\
\hline \multirow{6}{*}{$R_{2}=.13$} & Chinese & .00 & .14 & .05 & .96 \\
\hline & Female & .22 & .12 & 3.00 & $.00 * *$ \\
\hline & Undergraduate & -.16 & .11 & -2.03 & $.04 *$ \\
\hline & SES & .04 & .04 & .54 & .59 \\
\hline & Language competence & .17 & .02 & 2.08 & $.04 *$ \\
\hline & Domestic social support & .15 & .06 & 1.93 & .06 \\
\hline \multicolumn{6}{|c|}{ Purpose in life } \\
\hline \multirow{5}{*}{$R_{2}=.15$} & Chinese & -.17 & .13 & -2.11 & $.04 *$ \\
\hline & Female & .11 & .12 & 1.49 & .14 \\
\hline & Undergraduate & -.19 & .11 & -2.48 & $.01 *$ \\
\hline & SES & .03 & .04 & .39 & .70 \\
\hline & Language competence & .14 & .02 & 1.76 & .08 \\
\hline
\end{tabular}


Journal of International Students

\begin{tabular}{llllll}
\hline Outcome & Predictors & $\beta$ & $S E$ & $t$ & $p$ \\
\hline & Domestic social support & .16 & .06 & 2.15 & $.03^{*}$ \\
\hline Self-acceptance & & & & & \\
\hline \multirow{3}{*}{$R_{2}=.19$} & Chinese & -.09 & .12 & -1.14 & .26 \\
& Female & .12 & .11 & 1.73 & .09 \\
& Undergraduate & -.11 & .10 & -1.46 & .15 \\
& SES & .19 & .03 & 2.56 & $.01^{*}$ \\
& Language competence & .21 & .02 & 2.56 & $.01^{*}$ \\
& Domestic social support & .18 & .06 & 2.48 & $.01^{*}$ \\
\hline Psychological well-being & & & & \\
$R_{2}=.23$ & Chinese & -.05 & .53 & -.67 & .50 \\
& Female & .13 & .46 & 1.88 & .06 \\
& Undergraduate & -.17 & .44 & -2.32 & $.02^{*}$ \\
& SES & .13 & .15 & 1.79 & .08 \\
& Language competence & .25 & .08 & 3.25 & $.00^{* *}$ \\
& Domestic social support & .25 & .25 & 3.59 & $.00^{* * *}$ \\
\hline
\end{tabular}

Note. SES $=$ socioeconomic status. $* p<.05, * * p<.01, * * * p<.001$

\section{Perceived Language Competence, Domestic Student Social Support, and Well- Being}

The same seven regression equations were recalculated with the addition of domestic student social support as an independent variable (see Table 4). The two independent variables and four control variables accounted for $12 \%$ to $23 \%$ of the variance in well-being aggregate and subscales: psychological well-being $(23 \%)$, self-acceptance $(20 \%)$, autonomy $(16 \%)$, purpose in life $(15 \%)$, personal growth $(13 \%)$, positive relations with others $(12 \%)$, and environmental mastery $(11 \%)$. Perceived English competence was associated with six of the seven psychological well-being variables while domestic student social support was related to five of the seven well-being variables. In all instances, higher levels of perceived language competence and higher levels of domestic student support were associated with increases in well-being.

Table 4: Significant Predictors of Well-Being Outcomes

\begin{tabular}{|c|c|c|c|c|c|c|c|}
\hline Predictor & 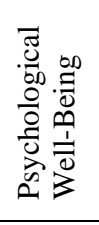 & 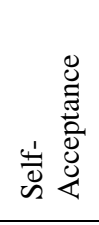 & 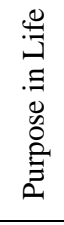 & 苛 & 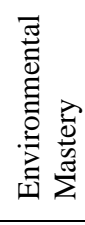 & 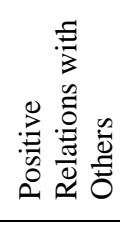 & 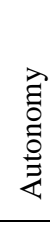 \\
\hline Chinese & & & - & & & & \\
\hline Female & & & & ++ & & & \\
\hline Undergraduate & - & & - & - & & & \\
\hline SES & & + & & & & & \\
\hline
\end{tabular}




\begin{tabular}{|c|c|c|c|c|c|c|}
\hline $\begin{array}{l}\text { Language } \\
\text { competence }\end{array}$ & ++ & + & & + & + & ++ \\
\hline $\begin{array}{l}\text { Domestic social } \\
\text { support }\end{array}$ & +++ & + & + & & ++ & ++ \\
\hline
\end{tabular}

Note. $+/$ - signifies the direction of the relationship between variables. $+/-<.05$, $++/--<.01,+++/---<.001$

\section{DISCUSSION}

The current study was designed to explore potential associations between demographic factors, domestic student social support, perceived language competence, and range of psychological well-being outcomes. Interestingly, the two independent variables of interest, domestic student social support and perceived language competence, did not correlate as hypothesized. This finding aligns with the current research, which has mixed results with regard to English competence and international student adjustment (positive relationship: Chavoshi et al., 2017; Dao et al., 2007; Lin \& Betz, 2009; no relationship: Poyrazli et al., 2004). We caution against overinterpretation of an acceptance of the null hypothesis, especially given the homogeneity of the sample in this modest study. Nonetheless it should be noted that the theoretical approach of focusing on international students' acculturation style is naturally incomplete: Domestic students may seek out specific international students for reasons other than their level of English and ability to communicate easily. Clearly more research is needed to understand the potential relationship between language competence and domestic social support.

With regard to the second hypothesis, perceived language competence was associated with higher levels of three aspects of well-being: self-acceptance, environmental mastery, and positive relations with others. As expected, students' perceptions of their English ability were linked with positive psychological wellbeing outcomes that require higher levels of language knowledge and interaction. Interestingly, perceived language competence was associated with higher levels of two other aspects of well-being, autonomy and personal growth, as well as overall psychological well-being. These findings add to the prior literature that has revealed that perceived language discrimination is predictive of negative mental health outcomes and lower life satisfaction on campus (Wei, Wang, \& Ku, 2012). Future investigations can determine the relative contributions of perceived language competency and perceived language discrimination to international students' wellbeing.

Domestic student social support was related to international student well-being. Three of the four hypothesized relationships were significant: environmental mastery, positive relations with others, and overall psychological well-being; additionally, domestic student social support predicted higher levels of self-acceptance and purpose in life. These findings align with prior research revealing that students who report high level of social connections experience lower levels of acculturation stress (Yeh \& Inose, 2003). However, there was not a significant relationship between social support and autonomy or personal growth. A non-relationship between social support 
and autonomy is not wholly surprising as one's perception of receiving help and support from other students could be connected with feeling that they cannot satisfy their needs alone autonomously.

The final hypothesis posited that domestic student social support would be a stronger predictor of each aspect of psychological well-being than perceived language competence due to the importance of members of the host society in the acculturation process. Results were mixed: Domestic student social support was a stronger predictor of purpose in life, positive relations with others, environmental mastery, and overall psychological well-being, while perceived language competence was a stronger predictor of autonomy, self-acceptance, and personal growth. Students with lower perceived language competence and language skills reported more academic difficulties and higher stress level. The adjustment process is slower for students with poor English competency. More social discomfort has been reported among these students (Duru \& Poyrazli, 2011).

\section{Limitations}

There are three main limitations of the current case study. First, the study was conducted with participants from only one U.S. university, making its generalizability limited. In this light, the study should be viewed as an exploration into identifying associations between important academic and social variables. Second, the study relied on a single item for perceived language competence. It would be preferable to have included a scale to increase confidence in construct measurement; however, available scales in the literature focus on anxiety, pronunciation, or communication, rather than English competence. Third, the data are cross-sectional; although the analyses test for prediction, it is important to remember that the predictions are associations rather than causal relationships.

\section{Implications for Research}

The current study extends current research by examining predictors of multiple aspects of well-being, yielding a more nuanced understanding of international student adjustment. Further, the current study provides additional empirical evidence supporting the use of individuals' perception of their language ability rather than solely objective measurements of language competence (e.g., standardized testing). From this perspective, researchers can develop a more detailed understanding of the ways in which language ability can potentially influence international student adjustment and well-being. Additionally, the current study extends research on social support to highlight the strength of associations between international students' psychological well-being and a particular source of social support: domestic students at their university.

If the findings of the current study are replicated, researchers might consider exploring differential impact of language and social factors on international student adjustment, given the lack a relationship between perceived language competence and domestic student social support. Previous research has documented well the various types of predictors of international student adjustment: linguistic, 
sociocultural, academic, discriminatory, and practical (Smith \& Khawaja, 2011). The findings of the current study also bolster the argument of J. Zhang and Goodson (2011) for the need to continue to refine Ward and colleagues' (Ward \& Kennedy, 1999; Ward \& Rana-Deuba, 1999) theory of cross-cultural adaptation. Given that both domestic student social support and perceived language competence shared strong associations with multiple aspects of psychological well-being, it may be time to construct a more nuanced and complex model, or consider integrating other developmental theories with strong bases of research for explaining adjustment, growth, and well-being such as life course theory (Elder \& Shanahan, 2006).

If the findings of the current study are replicated, researchers might consider beginning to test which factors are most predictive of international student adjustment so that interventions can be designed to provide campus life personnel and university administration with evidence-based highly effective resources to support international student adjustment.

\section{Implications for Practitioners}

As colleges and universities in the US continue to experience an increase of international students, the well-being of international students can no longer be solely the concern of the international or global office, but rather should be central to the operations of the university: in campus life, the research lab, and the classroom. Preorientation programs and first-year experience courses are well-suited to providing opportunities for international students to create friendships with domestic students as well as to enhance their language competence. Recent studies have demonstrated orientations and orientation-style programming for international students can increase their understanding of university mission and goals and general university adjustment (Güvendir, 2018; Y. Zhang \& Garcia-Murillo, 2018). Through provision structured opportunities for international students to interact with domestic students, international students can gain confidence of their English competence and connect with domestic students in orientations. More language-oriented programs can be held in the summer before the international students come to the US. If an institution has a large concentration of students from one or more countries, it may be worthwhile to consider creating country-specific programming or holding pre-orientation programming at a location in those countries, providing students the opportunity to begin their college transition without jetlag and with less potential for culture shock (Brunsting et al., 2017).

As for social support from domestic students, the practitioners are encouraged to create ways to encourage the conversations between international students and domestic students. For example, in the orientation week, there are often icebreakers designed to create social cohesion and opportunity for interaction. We encourage additional time be set aside for semi-structured social events. Pre-orientation programming focused on inclusion and diversity should be developed with an eye toward international student diversity in addition to that of domestic students. Additionally, university faculty and staff should reconsider their role in supporting international student adjustment to university, as they are often viewed by students as academic role models (Glass, Koliocek, Wongtriat, Lynch, \& Cong, 2015; Mesidor 
\& Sly, 2016). Domestic-international student interaction and dialogue on campus occurs frequently in classrooms and research labs (Glass, 2012); however, academic settings typically are the most challenging arenas of communication and English language expertise for international students (Yildirim, 2015). Although many faculty are welcoming of international students and are inclusive and supportive of their perspectives in class, others either miss opportunities to include international students in discussion or outright discourage those who have not fully mastered English (Glass et al., 2015; J. J. Lee \& Rice, 2007). We encourage informal discussions among faculty, department chairs, and deans around expectations and support of international student adjustment.

\section{Implications for International Students}

The results of this study underscore the importance of perceived language competence to international students' well-being at a U.S. university. Communication is a critical component for fitting into the environment for international students undergoing the acculturation process (Sam \& Berry, 2010). We recommend international students increase preparation in two focused areas prior to transition to U.S. universities: increasing English competence and understanding of social culture in the US. In order to build confidence and competence of one's English ability, international students should undergo a thorough and detailed evaluation that includes spoken English, academic writing, and reading speed at least one year prior to departing for university. Additional time spent shoring up language skills may yield increased confidence for international students when they arrive in the US. We encourage international students to engage in pre-orientation programs that are held by their universities, which can provide international students with opportunities to engage in the host environment so that they can be more familiar with the language and culture ahead of the first semester (Y. Zhang \& Garcia-Murillo, 2018). Experiencing success within the programs can increase confidence in their English ability. Additionally, gaining intercultural skills via introductory courses or other means can help increase international students' social support (Brunsting, Smith, \& Zachry, 2018). After enrolling on campus, we recommend international students continue to push themselves to engage in activities and build friendships with domestic students, as it provides a context to both continue to improve language competence and to receive social support (Brunsting et al., 2019; Glass, 2012; Han, Pistole, \& Caldwell, 2017; Lin \& Betz, 2009).

\section{CONCLUSION}

The current case study provides modest initial evidence of positive associations between perceived language competence and multiple aspects of psychological wellbeing as well as between domestic student social support and psychological wellbeing. Although the study is limited based on its participant sample studying at one university, the findings are promising. We encourage researchers, practitioners, and international students to consider a more nuanced, positive, and multifaceted approach toward understanding international student adjustment. 


\section{REFERENCES}

Alharbi, E., \& Smith, A. (2018). Review of the literature on stress and wellbeing of international students in English-speaking countries. International Education Studies, 11(6), 22-44.doi: 10.5539/ies.v11n6p22

Brunsting, N. C., Mischinski, M. M., Wu, W., Tevis, T., Takeuchi, R., He, Y., Zheng, Y., \& Coverdell, T. (2019) International students' social outcomes, educational status, and country of high school graduation. Journal of Studies in International Education, 23, 589-606.

Brunsting, N. C., Smart, J. W., Eisner, J., Liu, J., Coverdell, T. L., \& Sun, W. (2017). Arrive prepared: An Academic College Transition (ACT) program for precollege international students. E-Source for College Transitions, 15(1), 9-12.

Brunsting, N. C., Smith, A. C., \& Zachry, C. E. (2018). An academic and cultural transition course for international students: Efficacy and socio-emotional outcomes. Journal of International Students, 8(4), 1497-1521. doi: 10.32674/jis.v8i4.213

Brunsting, N. C., Zachry, C., \& Takeuchi, R. (2018). Predictors of undergraduate international student psychosocial adjustment to U.S. universities: A systematic review from 2009-2018. International Journal of Intercultural Relations, 66, 2 33.doi: $10.1016 /$ j.ijintrel.2018.06.002

Carver, C. S. (2006). Sources of Social Support Scale. Available at http://www.psy.miami.edu/faculty/ccarver/sclSSSS.html.

Chavoshi, S., Wintre, M. G., Dentakos, S., \& Wright, L. (2017). A developmental sequence model to university adjustment of international undergraduate students. Journal of International Students, 7(3), 703-727. doi: 10.5281/zenodo.570029

Ching, Y., Renes, S. L., McMurrow, S., Simpson, J., \& Strange, A. T. (2017). Challenges facing Chinese international students studying in the United States. Educational Research and Reviews, 12(8), 473-482. https://doi.org/10.5897/ERR2016.3106

Constantine, M. G., Okazaki, S., \& Utsey, S. O. (2004). Self-concealment, social selfefficacy, acculturative stress, and depression in African, Asian, and Latin American international college students. American Journal of Orthopsychiatry, 74(3), 230-241. https://doi.org/10.1037/0002-9432.74.3.230

Dao, T. K., Lee, D., \& Chang, H. L. (2007). Acculturation level, perceived English fluency, perceived social support, and depression among Taiwanese international students. College Student Journal, 41(2), 287-295.

de Araujo, A. A. (2011). Adjustment issues of international students enrolled in American colleges and universities: A review of the literature. Higher Education Studies, 1(1), 2-8. doi: 10.5539/hes.v1n1p2

Duru, E., \& Poyrazli, S. (2011). Perceived discrimination, social connectedness, and other predictors of adjustment difficulties among Turkish international students. International Journal of Psychology, 46(6), 446-454. https://doi.org/10.1080/00207594.2011.585158

Elder, G. H., \& Shanahan, M. J. (2006). The life course and human development. In R. M. Lerner \& W. Damon (Eds.), The handbook of child psychology: 
Theoretical models of human development (Vol 1., 6th ed., pp. 665-715). Hoboken, NJ: John Wiley \& Sons.

Glass, C. R. (2012). Educational experiences associated with international students' learning, development, and positive perceptions of campus climate. Journal of Studies in International Education, 16, 228-251.

Glass, C. R., Kociolek, E., Wongtriat, R., Lynch, R. J., \& Cong, S. (2015). Uneven experiences: The impact of student-faculty interactions on international students' sense of belonging. Journal of International Students, 5, 353-367.

Güvendir, M. A. (2018). The relation of an international student center's orientation training sessions with international students' achievement and integration to university. Journal of International Students, 8, 843-860. doi: 10.5281/zenodo. 1250385

Han, S., Pistole, M. C., \& Caldwell, J. M. (2017). Acculturative stress, parental and professor attachment, and college adjustment in Asian international students. Journal of Multicultural Counseling and Development, 45, 111-126.

Institute of International Education (2017). International student totals by place of origin, 2015/16-2016/17. Open Doors report on international educational exchange. Retrieved from http://www.iie.org./opendoors

Lee, J. J., \& Rice, C. (2007). Welcome to America? International student perceptions of discrimination. Higher Education, 53, 381-409.

Li, J., Wang, Y., \& Xiao, F. (2014). East Asian international students and psychological well-being: A systematic review. Journal of International Students, 4(4), 301-313.

Li, Z., Heath, M. A., Jackson, A. P., Allen, G. E. K., Fischer, L., \& Chan, P. (2017). Acculturation experiences of Chinese international students who attend American universities. Professional Psychology: Research \& Practice, 48(1), 11-21._doi: $10.1037 /$ pro0000117

Lin, S.-P., \& Betz, N. E. (2009). Factors related to the social self-efficacy of Chinese international students. Counseling Psychologist, 37(3), 451-471. https://doi.org/10.1177/0011000009332474

Longerbeam, S. D., DeStefano, T. J., \& Lixin, Y. (2013). "We cannot reach them": Chinese undergraduate student perceptions of the U.S. campus climate. Journal of Student Affairs Research and Practice, 50, 326-344.

MacLachlan, D. A., \& Justice, J. (2009). A grounded theory of international student well-being. Journal of Theory Construction \& Testing, 13, 27-32.

Mak, A. S., Bodycott, P., \& Ramburuth, P. (2015). Beyond host language proficiency: Coping resources predicting international students' satisfaction. Journal of Studies in International Education, 19(5), 460-475._doi: $10.1177 / 1028315315587109$

Mesidor, J. K., \& Sly, K. F. (2016). Factors that contribute to the adjustment of international students. Journal of International Students, 6, 262-282.

Poyrazli, S., \& Grahame, K. M. (2007). Barriers to adjustment: Needs of international students within a semi-urban campus community. Journal of Instructional Psychology, 34, 28-45. 
Poyrazli, S., Kavanaugh, P. R., Baker, A., \& Al-Timimi, N. (2004). Social support and demographic correlates of acculturative stress in international students. Journal of College Counseling, 7(1), 73-82.

Ryff, C. D. (1989a). Happiness is everything or is it explorations on the meaning of psychological well-being. Journal of Personality and Social Psychology, 57, 1069-1081.

Ryff, C. D. (1989b). Beyond Ponce de Leon and life satisfaction: New directions in quest of successful ageing. International Journal of Behavioral Development, 12(1), 35-55.

Sam, D. L., \& Berry, J. W. (2010). Acculturation: When individuals and groups of different cultural backgrounds meet. Perspectives on Psychological Science, 5, 472-481.

Smith, R. A., \& Khawaja, N. G. (2011). A review of the acculturation experiences of international students. International Journal of Intercultural Relations, 35, 699713.

Sümer, S., Poyrazli, S., \& Grahame, K. (2008). Predictors of depression and anxiety among international students. Journal of Counseling and Development, 86(4), 429-437.

Wang, C.-C. D., \& Mallinckrodt, B. (2006). Acculturation, attachment, and psychosocial adjustment of Chinese/Taiwanese international students. Journal of Counseling Psychology, 53(4), 422-433. https://doi.org/10.1037/00220167.53.4.422

Wang, K. T., Heppner, P. P., Fu, C.-C., Zhao, R., Li, F., \& Chuang, C.-C. (2012). Profiles of acculturative adjustment patterns among Chinese international students. Journal of Counseling Psychology, 59(3), 424-436. https://doi.org/10.1037/a0028532

Ward, C., \& Kennedy, A. (1999). The measurement of sociocultural adaptation. International Journal of Intercultural Relations, 23, 659-677.

Ward, C., \& Rana-Deuba, A. (1999). Acculturation and adaptation revisited. Journal of Cross-Cultural Psychology, 30, 422-442.

Ware, W. M., Ferron, J. M., \& Miller, B. M. (2013). Introductory statistics: A conceptual approach using $R$. New York, NY: Routledge.

Wei, M., Wang, K. T., \& Ku, T.-Y. (2012). A development and validation of the Perceived Language Discrimination Scale. Cultural Diversity and Ethnic Minority Psychology, 18(4), 340-351. https://doi.org/10.1037/a0029453

Yeh, C. J., \& Inose, M. (2003). International students' reported English fluency, social support satisfaction, and social connectedness as predictors of acculturative stress. Counselling Psychology Quarterly, 16(1), 15-28. https://doi.org/10.1080/0951507031000114058

Yildirim, O. (2015). English related difficulties experienced by Turkish students studying in a dual diploma ELT program in the U.S.A. Journal of International Education Research, 11, 107-118.

Zhang, J., \& Goodson, P. (2011). Predictors of international students' psychosocial adjustment to life in the United States: A systematic review. International Journal of Intercultural Relations, 35(2), 139-162. https://doi.org/10.1016/j.ijintrel.2010.11.011 
Zhang, Y. \& Garcia-Murillo, M. A. (2018). Improving international students' cultural skills through a school-based program. International Research and Review: Journal of Phi Beta Delta Honor Society for International Scholars, 7(2), 42-64.

ZHENGDA LUO is an undergraduate research assistant at the Academic and Cultural Transition Research team at Wake Forest University, Winston-Salem, North Carolina, USA. His major research interests lie in international students' wellbeing and social adjustment in U.S. higher education setting. Email: luoz17@wfu.edu

SIYU WU is an undergraduate research assistant at the Academic and Cultural Transition Research team at Wake Forest University, Winston-Salem, North Carolina, USA. Her major research interests lie in international students' language proficiency and social adjustment as an outcome in the U.S. higher education. Email:wus217@wfu.edu

XUANYU FANG is an undergraduate research assistant at the Academic and Cultural Transition Research team at Wake Forest University, Winston-Salem, North Carolina, USA. His major research interests lie in international students' acculturation process and psychological wellbeing. Email: fangx17@wfu.edu

NELSON BRUNSTING, PhD, is the Director of Global Research and Assessment in the Center for Global Programs and Studies at Wake Forest University, WinstonSalem, North Carolina, USA. His research is focused on understanding the socioemotional development of diverse populations in educational settings. Email: brunstnc@wfu.edu 